\title{
Effective Vibration-based Condition Monitoring (eVCM) of Rotating Machines
}

DOI:

10.1108/JQME-08-2016-0036

\section{Document Version}

Accepted author manuscript

Link to publication record in Manchester Research Explorer

\section{Citation for published version (APA):}

Yunusa-Kaltungo, A., \& Sinha, J. (2017). Effective Vibration-based Condition Monitoring (eVCM) of Rotating Machines. Journal of Quality in Maintenance Engineering. https://doi.org/10.1108/JQME-08-2016-0036

\section{Published in:}

Journal of Quality in Maintenance Engineering

\section{Citing this paper}

Please note that where the full-text provided on Manchester Research Explorer is the Author Accepted Manuscript or Proof version this may differ from the final Published version. If citing, it is advised that you check and use the publisher's definitive version.

\section{General rights}

Copyright and moral rights for the publications made accessible in the Research Explorer are retained by the authors and/or other copyright owners and it is a condition of accessing publications that users recognise and abide by the legal requirements associated with these rights.

\section{Takedown policy}

If you believe that this document breaches copyright please refer to the University of Manchester's Takedown Procedures [http://man.ac.uk/04Y6Bo] or contact uml.scholarlycommunications@manchester.ac.uk providing relevant details, so we can investigate your claim.

\section{OPEN ACCESS}




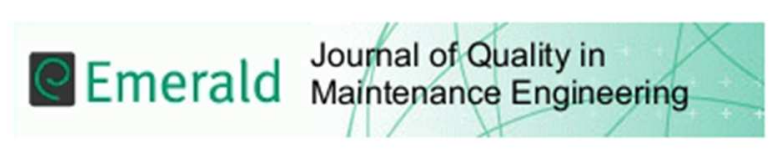

\section{Effective Vibration-based Condition Monitoring (eVCM) of Rotating Machines}

\begin{tabular}{|r|l|}
\hline Journal: & Journal of Quality in Maintenance Engineering \\
\hline Manuscript ID & JQME-08-2016-0036.R1 \\
\hline Manuscript Type: & Research Paper \\
\hline Keywords: & $\begin{array}{l}\text { maintenance optimisation, eMaintenance, rotating machines, condition- } \\
\text { based maintenance, data combination, pattern classification }\end{array}$ \\
\hline \multicolumn{2}{|l}{} \\
\hline
\end{tabular}


Effective Vibration-based Condition Monitoring (eVCM) of Rotating Machines

\author{
Akilu Yunusa-Kaltungo*, Jyoti K. Sinha \\ Reliability Engineering and Asset Management Programme, School of Mechanical, Aerospace and Civil Engineering, The University of \\ Manchester, Manchester M13 9PL, UK. \\ E-mail addresses: akilu.kaltungo@manchester.ac.uk (A. Yunusa-Kaltungo), jyoti.sinha@manchester.ac.uk (J.K. Sinha)
}

\begin{abstract}
- Purpose
\end{abstract}

The purpose of this paper is mainly to highlight how a simplified and streamlined approach to the condition monitoring of industrial rotating machines through the application of frequency domain data combination can effectively enhance the eMaintenance framework.

\title{
- Design/methodology/approach
}

The paper commences by providing an overview to the relevance of maintenance excellence within manufacturing industries, with particular emphasis on the roles that rotating machines condition monitoring of rotating machines plays. It then proceeds to provide details of the eMaintenance as well as its possible alignment with the introduced concept of effective vibration-based condition monitoring $(\mathrm{eVCM})$ of rotating machines. The subsequent sections of the paper respectively deal with explanations of data combination approaches, experimental setups used to generate vibration data and the theory of eVCM.

- Findings

This paper investigates how a simplified vibration-based rotating machinery faults classification method based on frequency domain data combination can increase the feasibility and practicality of eMaintenance.

\section{- Research limitations/implications}

The eVCM approach is based on classifying data acquired under several experimentally simulated conditions on two different machines using combined higher order signal processing parameters so as to reduce condition monitoring data requirements. Although the current study was solely based on the application of vibration data acquired from rotating 
machines, the knowledge exchange platform that currently dominates present day scientific research makes it very likely that the lessons learned from the development of eVCM concept can be easily transferred to other scientific domains that involve continuous condition monitoring such as medicine.

- Practical implications

The concept of eMaintenance as a cost-effective and smart means of increasing the autonomy of maintenance activities within industries is rapidly growly in maintenance related literatures. As viable as the concept appears, the achievement of its optimum objectives and full deployment to the industry is still subjective due to the complexity and data intensiveness of conventional condition monitoring practices. In this paper, an effective vibration-based condition monitoring (eVCM) approach is proposed so that rotating machine faults can be effectively detected and classified without the need for repetitive analysis of measured data.

\section{- Social implications}

The main strength of eVCM lies in the fact that it permits the sharing of historical vibration data between identical rotating machines irrespective of their foundation structures and speed differences. Since eMaintenance is concerned with driving maintenance excellence, eVCM can potentially contribute towards its optimisation as it cost-effectively streamlines faults diagnosis. This therefore implies that the simplification of vibration-based condition monitoring of rotating machines positively impacts the society with regards to the possibility of reducing how much time is actually spent on the accurate detection and classification of faults.

\section{- Originality/value}

Although the currently existing body of literature already contains studies that have attempted to show how the combination of measured vibration data from several industrial machines can be used to establish a universal vibration-based faults diagnosis benchmark for incorporation into eMaintenance framework. However, these studies are limited in the scope of faults, severities and rotational speeds considered. In the current study, the concept of multi-faults, multi-sensor, multi-speed and multi-rotating machine data combination approach using frequency domain data fusion and principal components analysis is presented so that faults diagnosis features for identical rotating machines with different foundations can be shared between industrial plants. Hence, the value of the current study particularly lies in the fact that it significantly highlights a new dimension through which the practical 
implementation and operation of eMaintenance can be realised using big data management and data combination approaches.

\section{Keywords}

Maintenance optimisation; eMaintenance; rotating machines; condition-based maintenance; data combination; pattern classification.

\section{Introduction}

The rapid and continuous growth in the globalisation of most industrial operations has significantly shifted the paradigm of competitiveness away from monopoly and more towards perfect competition. The pressures exerted by this paradigm shift are immense, especially in the areas of waste elimination and the implementation of cost-effective strategies that can avert or significantly minimise critical plant downtimes. The fundamental objective of most organisations is the transformation of raw materials into finished products, which may be tangible or non-tangible. The effective achievement of this transformation process requires that the influence of crucial elements such as men, machines, methods, materials and money (i.e. the 5Ms) is well-managed. The burden of managing an industrial plant grossly rests on the shoulders of two key plant functions, namely production and maintenance. Traditionally, the production function is directly concerned with the generation of the finished goods from the various raw materials. This invariably implies that the production function is the custodian of all machines which is perhaps why production is arguably referred to as the main reason for the existence of most manufacturing organisations. However, owing to a highly dynamic operational environment (e.g. load and speed variations), virtually all industrial machines are susceptible to failures which lead to plant downtimes.

In a study conducted by Eti et al [1], it was reported that even the world's best performing organisations within the chemical industry still incur annual maintenance costs of up to $1-2 \%$ of the present replacement values of their plant assets. On the other hand, organisations with less efficient maintenance management systems can incur costs in excess of 5\% of the present asset replacement value. In other industries, the cost of inefficient maintenance practices can be more severe to organisations. For instance, Mckone and Weiss [2] stated in their study that the company-wide spending on maintenance by some organisations could be equivalent to their net income especially when the indirect impacts of maintenance (e.g. loss of income as a 
result of failures, substandard product quality, drop in market shares, loss of customers' confidence, etc.) are adequately considered [3-10]. Maintenance activities are widely regarded as deterrents to plant downtimes since they incorporate repair and/or replacement plans for asset failures. Hence, maintenance is a vital support function in the raw materials transformation process in any manufacturing organisation. In the past, the maintenance functions of most organisations were mainly viewed as problem-solvers that primarily exist for the purpose of rescuing the plant when production problems arose. During these times (also known as the "fix it when it breaks" era), organisations were happy for machine failures to occur before maintenance interventions were initiated. This approach was probably acceptable because customer demands for goods and services significantly outweighed supply [11]. Also, the profit margins for organisations were very high and fewer safety requirements from regulatory authorities [9-13]. On the contrary, present day organisations are faced with very harsh global competitions, slimmer profit margins, significantly higher safety awareness and tougher environmental regulations [12-13].

In order to meet the current and briskly changing industrial trends, maintenance strategies have evolved from the "fix it when it breaks down" era where organisations could afford huge number of spare parts and workforce, to an era of eMaintenance whereby strategies such as remote condition monitoring $(\mathrm{CM})$ are constantly considered. Using a vital class of plant assets such as rotating machines (e.g. compressors, fans, rotary kilns, roller mills, turbines, pumps, etc.) as an example, CM is a maintenance strategy that aims to initiate repair and/or replace actions only based on proven deviations from acceptable operational standards of such an asset. The success of any CM strategy depends on its ability to accurately detect incipient faults within the usual constraints of the $5 \mathrm{Ms}$. Because rotating machines are very versatile, they operate under various industrial environments which often lead to emergence faults including misalignment, bends, cracks, looseness, gear train malfunctions, electric motor faults, bearing faults, soft foot, unbalance, etc. Some of the most commonly used CM techniques for rotating machines in practice include vibration monitoring, temperature monitoring, acoustic emission, lubrication and wear debris monitoring, power consumption monitoring, etc. Despite the significance of the achievements recorded using each of these $\mathrm{CM}$ techniques, vibration-based condition monitoring (VCM) of rotating machines is still miles ahead in terms of applicability and popularity. This is owing to its ability to provide the reasonable lead-time to the failure for most rotating machines [14-16]. 
Within the last three decades, industrial and academic maintenance experts have introduced various maintenance optimisation approaches such as eMaintenance [17-18] and intelligent prognostic tools [19-22].

For instance, Galar et al. [23] realised that the existing rules for rotating machine condition monitoring provided by original equipment manufacturers (OEM) are often static and do not necessary reflect age and operational context of the machine, which sometimes trigger unnecessary maintenance interventions. In order to allow plants focus on actual machine failure-causing tasks, the study [23] proposed two new features (overall factory vibration level and overall factory averaged spectrum) based on the combination of vibration data measured from all orthogonal directions of pump bearings. Studies by Emmanouilidis et al. [24] and Baglee et al. [25] have also proposed abstract frameworks for eMaintenance based on the combination key asset management elements. The study by Emmanouilidis et al. [24] particularly emphasized the need for integrating processes (i.e. novelty detection, diagnostics and prognostics) and ontology (systematic maintenance diagnostic knowledge) whereby the ontology element would form the basis for generating domain knowledge as well as the data that correspond to various CM activities. The process element on the other hand represents the components that connect different domain concepts (e.g. rotating machine health indicators, useful life, etc.) to the real-life data acquired from measurements, using an incremental knowledge development technique. As interesting as the findings from some of these studies are [23], their experimental and/or industrial cases are either focussed on few machine operating conditions (faults, operating speeds and foundation types) or based on abstract frameworks that still require data and quantifiable results to ascertain their practicability [24-25].

Owing to the fact that common industry-based VCM of rotating machines still entails the analysis of numerous vibration data from individual measurement locations. In fact, the advent of plant standardisation as a cost-effective means of rationalising spare parts has made the job of $\mathrm{CM}$ analysts more arduous, since they are now required to acquire and analyse VCM data for various identical machines possessing different dynamic behaviours due to varying speeds and foundation installation requirements in different plant locations. Based on this premise, the development of an effective vibration-based condition monitoring (eVCM) approach that is capable of detecting and classifying the different conditions under which rotating machines are operating irrespective of their foundation configurations and speeds would be very useful for the implementation of efficient maintenance management strategies 
for industrial rotating machines. Through the application of vibration data measured from a laboratory scale experimental rig under different experimentally simulated cases, the cornerstone of this paper is to present an overview of eVCM of rotating machines and its potential place within the eMaintenance framework.

\section{The Concept of eVCM and its Alignment with eMaintenance}

eMaintenance is a term that emerged within the last two decades and has been continuously associated with various maintenance literatures [26]. According to Baldwin [27], eMaintenance refers to the proper integration of all activities (i.e. maintenance strategy, maintenance plan, maintenance type and maintenance support) that would lead to the achievement of excellent maintenance, which is also illustrated by this simple relationship [27];

eMaintenance $=$ Excellent maintenance $=$ Efficient maintenance + Effective maintenance + Enterprise maintenance

A very interesting and valuable aspect of the eMaintenance framework is its potential to offer organizations the means of proactively assessing incipient degradation of the health of their critical assets so as to initiate maintenance actions that would significantly reduce the probability of costly downtimes [28-31]. The recent advancements in information technology and computational power have triggered the improved smartness of maintenance strategy and/or plan (eMaintenance) thereby enhancing its ability to effectively support production (eManufacturing) and business (eBusiness) in general. An important element of eBusiness is eProcurement as well as the implementation of rationalised eStores [27], which is most commonly achieved by standardising plant assets. For instance, a typical global cement manufacturing company could install a particular brand of roots blowers across all its plant sites so as to cost-effectively optimise its spare parts holding costs. While such an approach may initially appear to fit properly into the overall eManufacturing and eBusiness strategies, the eMaintenance component is still far from being top-notch due to a lack of truly intelligent fault detection and diagnosis process for critical industrial assets such as rotating machines. Based on this premise, the development of a VCM technique which is insensitive to changing speeds is highly justified. In addition to changing speeds, there exist practical scenarios whereby identical rotating machines possess slightly different dynamic behaviours owing to variations in the flexibilities of their foundation structures. Referring back to the example of 
the cement process plant roots blowers, a multiple speeds roots blower installed on the rooftops of certain parts of the plant might require specialised vibration isolation dampers in comparison to similar roots blowers installed on plant floors. While significant levels of developments have been attained with VCM techniques that focus on transient machine operations, it remains doubtful that well-established data processing techniques would be robust enough to handle continuous operations with variable speeds [31].

Currently, the detection of faults under the scenarios of identical multiple speeds machines with different supports would involve separate analysis of measured vibration data for each machine (e.g. roots blower 1 with steel foundation, roots blower 2 with concrete foundation, roots blowers $3 \& 4$ mounted on vibration isolators as shown in Figure 1 [32-36]) at different speeds and plant locations. Therefore, if a typical cement manufacturing organisation owns 2 separate cement plants and each of the plants transports fine materials through the aid of 3 multiple speeds roots blowers, as many as 30 different sets of measured vibration data could be available for analysis each time a $\mathrm{CM}$ analyst performs routine data collection. It is obvious that continuously monitoring several multiple speeds identical rotating machines with conventional VCM techniques (e.g. amplitude spectrum, rotor orbits, waterfall analysis, bode plots, etc.) will be highly complicated and data intensive, which can further impede the achievement of the goals of eMaintenance.

Data combination in engineering is not exactly new and can be broadly associated with any process that involves the fusion of data and knowledge from several sources so as to significantly enhance the valuable information content of the resultant data [38]. Besides the ability of typical data combination approaches to enhance resultant information by fusing data from various sources, their success is also judged by how much they are able to rationalise the amount of resultant data retained especially with the currently growing trend of big data management.

Various existing studies [38-40] on data combination have already stipulated that data combination can be performed at raw signal, parameter and decision levels. Data combination at the raw signal level typically entails the complete fusion of measured raw data from all the sensors installed on the monitored machine after which a unique health monitoring parameter will be adequately extracted [38]. This type of data combination has the merit of containing maximum diagnosis information and has the capability of providing reasonably good 
outcomes [39]. On the other hand, a pre-requisite to the success of faults classification based on this approach is that the measured quantities must be very identical [39-40]. In reality, there is several machine condition monitoring techniques available for capturing the detection of different operating parameters of machines.

For instance, accelerometers, displacement probes and velocity transducers are used to capture vibration; thermocouples are used to detect temperature variations; microphones are used to capture changes in machine sounds; etc. In most cases, the information extracted from each of these CM sensors are not directly comparable which makes data combination at the raw signal level very difficult. Based on this restriction, data combination at this level initially requires the separate extraction of parameters from individual CM sensors according to the type of raw signal they generate $[38,40]$. The individual parameters extracted are then combined together at a later stage of the process after which pattern recognition is performed. The third type/level of data combination (i.e. decision level data combination) is an advancement of the second whereby data fusion only occurs after pattern recognition has been performed on the data sets measured by individual sensors. The individual patterns are then combined together using techniques such as behaviour knowledge space (BKS), Bayesian method, Dempster-Schafer theory, etc. [38].

Similarly, eVCM attempts to address the limitations of repeatedly performing separate rotating machine VCM analysis at individual measurement locations by using three distinct but closely related fronts of frequency domain data combination. At this initial stage of investigating the potential of simplifying machine faults detection through eVCM, only vibration data sets acquired using similar accelerometers (e.g. similar dynamic ranges, model, natural frequencies, mounting techniques, cabling, data acquisition system, power supply and signal processing software) were considered which implies that all quantities are similar.

\section{Multiple measurement transducers data combination}

In practice, VCM of industrial rotating machines often originates from the acquisition of vibration data from several predefined locations (usually the bearing pedestal) through the aid of sensors (e.g. accelerometers, proximity probes, etc.). The initial stage of eVCM involves the frequency domain fusion of all such measured vibration data to generate a single composite higher order spectrum [41]. The resultant unified spectrum provides a representation of the dynamic characteristics of the entire rotating machine, irrespective of the number of measurement locations. This in turn eliminates the process of analysing 
numerous spectra constructed from individual measurement locations as often required by current techniques. Since the data fusion involves higher order spectra [41], each fault diagnosis component is associated with amplitude and phase thereby reducing the number of sensors required.

\section{Multiple machine speeds data combination}

The next stage of the eVCM process relates to the combination of the respective unified features generated in stage 1 at the different speeds of a solitary rotating machine, thereby creating a multiple speed approach, which again eliminates the need for separate analysis at individual machine speed. This stage allows the conduction of rotating machine faults diagnosis based on features collected at a certain speed for the same machine when operating at other speeds.

\section{Multiple machine supports data combination}

At the final stage of eVCM, pattern classification techniques are used to integrate stages 1 and 2 for various similarly configured multiple speeds rotating machines but possessing different foundation structures. At this stage, the results of earlier faults diagnosis performed for a particular multiple speeds rotating machine can be shared between similarly configured rotating machines irrespective of their foundation differences thereby promoting experiential learning as well as eliminating the need for holding machine specific database of vibration measurements. The technique detects and classifies measured vibration data relating to different rotating machine operating conditions into different clusters. For instance, all vibration data collected under a relatively healthy machine condition will remain in the same healthy cluster for as long as the machine remains in that state. Once the state of the machine begins to change due to a certain fault, subsequent data will begin to migrate to a separate cluster that corresponds to that particular fault.

eVCM exhibits immense potentials needed for the optimisation of the already developed eMaintenance concept since it cost-effectively simplifies faults detection and classification of rotating machines. With the successful implementation of eVCM, organisations do not necessarily need to engage the services of experienced CM analysts as part of their day-today maintenance endeavours, since the need for complex analysis will be automatically governed by the migration of measured vibration data from healthy to faulty state. Figure 2 shows a schematic layout of the main elements of eVCM and its potential place within the eMaintenance framework. 


\section{Experimental Investigation of the Application of eVCM}

In order to practically observe the applicability of eVCM, two identical rotating rigs with different foundation structures were used for a pilot study. On both rigs, measured vibration data were collected from four bearing locations under different conditions of health (e.g. relatively healthy $(\mathrm{C} 1)$, misalignment $(\mathrm{C} 2)$, bent shaft $(\mathrm{C} 3)$, rubbing shaft $(\mathrm{C} 4)$, bearing looseness (C5) and shaft with breathing crack (C6)) and at three distinct machine speeds (i.e. $1200 \mathrm{rev} / \mathrm{min}, 1800 \mathrm{rev} / \mathrm{min}$ and $2400 \mathrm{rev} / \mathrm{min}$ ). For further clarity, Figure 3 presents a matrix of all the data generated from all experimentally simulated scenarios of speeds and machine conditions on both rigs.

The six machine conditions represent some of the most commonly encountered rotor-related faults in practice and were simulated under very similar conditions for each of the rigs. As earlier stated, the two experimental rigs investigated in the current study are very identical in their configurations and components; however, they differ in the flexibilities of their bearing supports. This variation in the bearing support flexibilities is mainly aimed at investigating the possibility of effectively developing a faults classification technic that can cater for the need of several identically configured industrial rotating machines despite variations in their foundation requirements, which would significantly ease faults diagnosis and eventually reduce machine repair/replace times. The difference in foundation flexibilities was experimentally simulated by changing the thickness of the threaded bars used for mounting the bearings (i.e. $10 \mathrm{~mm}$ and experimental rig 1 and $6 \mathrm{~mm}$ thickness for experimental rig 2). Figure 4 (a) shows the configuration as well as the various components of only one of the experimental rigs used for eVCM pilot study, while Figure 4 (b) provides detailed rig dimensions. On both experimental rigs and under all conditions of speed and simulated faults, four accelerometers (one per bearing pedestal) with sensitivities of $100 \mathrm{mV} / \mathrm{g}$ and frequency range of $10 \mathrm{kHz}$ was used to measure vibration. Prior to the commencement of the experiments, all sensors were manufacturer calibrated to error levels of less than $0.3 \%$ so as to ensure consistency and repeatability.

\section{4. eVCM Faults Classification Parameters}


On each of the experimental rigs, 20 distinct sets of vibration measurements were simultaneously obtained from each of the four bearing locations under $\mathrm{C} 1$ condition at three speeds. The same process was then repeated for each of the five fault conditions (i.e. C2, C3, C4, C5 and C6) thereby providing a total of 360 vibration measurements. This approach was aimed at imitating practical industrial CM of rotating machines whereby a typical CM analyst performs routine vibration measurements from two identical rotating machines installed at two different plant locations (as depicted by Figure 1) over a period of time (e.g. one measurement per week for 20 weeks), under changing operating (e.g. speed and loading) and health conditions. In order to generate the appropriate fault classification parameters that would effectively highlight the dynamic behaviours of the experimental rigs under the different conditions, each of the 360 measured time-domain vibration data were converted to the frequency-domain using the well-known fast Fourier transformation (FFT) process. During the FFT process, the following signal processing parameters were applied;

- $\quad$ sampling frequency of $10,000 \mathrm{~Hz}$

- data segment overlap of 0.95

- 148 segment averages

- $\quad 16,384$ data points in each FFT segment

- Frequency resolution of $0.6104 \mathrm{~Hz}$

Analysis in the frequency-domain allows for the quick and easy identification of frequency contents of interest (also known as harmonics) which should appear unique for individual machine conditions. However, analysis in frequency-domain using the well-known amplitude spectrum method is limited by the fact that only amplitude information of the spectral features are available, since all phase information is lost as a result of the magnitude squared operation associated with the computational process [14]. This is why several vibration sensors are often required at different orthogonal axes during the collection of vibration data which in turn increases faults diagnosis time and rigour. As an illustration, Figure 5 shows typical amplitude spectra for six of the experimentally simulated machine conditions (i.e. $\mathrm{C} 1$, C2, C4 and C6) at $2400 \mathrm{rev} / \mathrm{min}$ machine speed. It can be seen that the amplitude patterns of the various peaks displayed in Figures 5 (a) and 5 (d) are very similar despite the wide variations in the states of health of the experimental rig under both conditions. This similarity is mainly due to the fact that amplitude spectra analysis is based on a comparison of just magnitudes at individual frequencies, which may be similar for different machine conditions or even possess different spectral features for same machine condition at different speeds. 
Another popular dimension to the determination of changing operating conditions of rotating machines is rotor orbits analysis which involves the combination of the maximum vibration displacement (also known as peak-to-peak) of a rotating shaft in two orthogonal directions. It is believed that different machine faults should exhibit their own rotor orbit shapes which should be clearly different from that exhibited by other faults and most importantly that of a healthy machine. For further clarity, the rotor orbit plots for the cases (i.e. C1, C2, C4 and C6) shown in Figure 5 are similarly presented in Figure 6, where it can also be seen that with the exception of case $\mathrm{C} 6$, all other rotor orbit shapes are identical which makes classification impossible.

These inconsistencies make the development of a robust, reliable and time-saving fault diagnosis process impossible when using well-established VCM techniques such as amplitude spectra and rotor orbit analyses individually. As a means of practically improving the reliability of rotating machine fault diagnosis, vibration analysts often result to the combination of various conventional VCM methods including shaft orbits analysis, amplitude spectrum analysis, full spectrum analysis, bode plots, etc., so as to make up for the limitations of any particular one of the techniques. The achievements of the integration of various VCM techniques has been commendable over the past few decades especially in the aspect of providing tangible understanding to the complex behaviours of industrial machines and structures under changing operating conditions. However, the current global drives to continuously reduce the waiting time elements (particularly due to very complex and prolonged fault detection and diagnosis processes) of repair times makes it imminent for both academia and industry to develop simplified VCM methods that are capable of reducing the complexity of faults classification with significantly fewer sensor and data requirements.

To achieve these objectives, the parameters used for faults classification in the current study are based on higher order spectra (mainly bispectrum and trispectrum), since they retain both amplitude and phase information associated with each faults diagnosis parameter. This amplitude-phase retaining capability of higher order spectra (HOS) also offers a platform for sensor reduction, which eventually contributes to the current global efforts of big data management through data combination. 


\subsection{Methodology for eVCM parameter estimation process}

The initial stage of the process involves the computation of the Fourier transformation (FT) on each of the equal segments of vibration data acquired from each bearing location (b1-b4) at a particular frequency, which is then combined with those similarly computed at other bearing locations. It is very common in practice to have unwanted measurement noise associated with rotating machine vibration data. Hence, the algorithm developed has been incorporated with the coherence function between two successive measurement locations to help suppress uncorrelated noise. The data combination process generates a single composite spectrum that accurately offers insight into the dynamic behaviour of the monitored rotating machine or structure, irrespective of the population of the vibration data collection sources used as shown in Equations (1)-(3) [41].

$$
\begin{gathered}
\mathrm{S}_{\mathrm{pCCS}}\left(\mathrm{f}_{\mathrm{k}}\right)=\left(\frac{\left.\sum_{\mathrm{r}=1}^{\mathrm{n}_{\mathrm{s}}} \mathrm{X}_{1}^{\mathrm{r}}\left(\mathrm{f}_{\mathrm{k}}\right) \gamma_{12}^{2} \mathrm{X}_{2}^{\mathrm{r}}\left(\mathrm{f}_{\mathrm{k}}\right) \gamma_{23}^{2} \mathrm{X}_{3}^{\mathrm{r}}\left(\mathrm{f}_{\mathrm{k}}\right) \gamma_{34}^{2} \mathrm{x}_{4}^{\mathrm{r}\left(\mathrm{f}_{\mathrm{k}}\right)}\right)^{(1 / 4)}}{\mathrm{n}_{\mathrm{s}}}\right. \\
\mathrm{B}\left(\mathrm{f}_{\mathrm{l}}, \mathrm{f}_{\mathrm{m}}\right)=\frac{\sum_{\mathrm{r}=1}^{\mathrm{n}_{\mathrm{s}}}\left(\mathrm{x}_{\mathrm{pCCS}}^{\mathrm{r}}\left(\mathrm{f}_{1}\right) \mathrm{X}_{\mathrm{pCCS}}^{\mathrm{r}}\left(\mathrm{f}_{\mathrm{m}}\right) \mathrm{X}_{\mathrm{pCCS}}^{\mathrm{r}^{*}}\left(\mathrm{f}_{\mathrm{l}}+\mathrm{f}_{\mathrm{m}}\right)\right)}{\mathrm{n}_{\mathrm{s}}} \\
\left.\mathrm{T}\left(\mathrm{f}_{\mathrm{l}}, \mathrm{f}_{\mathrm{m}}, \mathrm{f}_{\mathrm{n}}\right)=\frac{\sum_{\mathrm{r}=1}^{\mathrm{n}_{\mathrm{s}}}\left(\mathrm{X}_{\mathrm{pCCS}}^{\mathrm{r}}\left(\mathrm{f}_{1}\right) \mathrm{X}_{\mathrm{pCCS}}^{\mathrm{r}}\left(\mathrm{f}_{\mathrm{m}}\right) \mathrm{X}_{\mathrm{pCCS}}^{\mathrm{r}}\left(\mathrm{f}_{\mathrm{n}}\right) \mathrm{X}_{\mathrm{pCCS}}^{\mathrm{r}^{*}}\left(\mathrm{f}_{1}+\mathrm{f}_{\mathrm{m}}+\mathrm{f}_{\mathrm{n}}\right)\right)}{\mathrm{n}_{\mathrm{s}}}\right)
\end{gathered}
$$

$\mathrm{X}_{1}^{\mathrm{r}}\left(\mathrm{f}_{\mathrm{k}}\right), \mathrm{X}_{2}^{\mathrm{r}}\left(\mathrm{f}_{\mathrm{k}}\right), \mathrm{X}_{3}^{\mathrm{r}}\left(\mathrm{f}_{\mathrm{k}}\right)$ and $\mathrm{X}_{4}^{\mathrm{r}}\left(\mathrm{f}_{\mathrm{k}}\right)$ in Equation (1) respectively represent the Fourier transformation $(\mathrm{FT})$ of the $\mathrm{rth}$ segment at frequency $\mathrm{f}_{\mathrm{k}}$ of the vibration data measured at bearings 1, 2, 3 and 4. Also, $\gamma_{12}^{2}, \gamma_{23}^{2}$ and $\gamma_{34}^{2}$ signify the coherences between successive measurement locations. Further details of the mathematical expressions that show the relationship that exists between all the variables used to develop eVCM faults classification parameters have been duly introduced in earlier studies by Yunusa-Kaltungo et al [15, 4142]. Figure 7 also presents a diagrammatic summary of the data combination process so that readers of the current study can better appreciate the concept. 
After the data combination process shown in Figure 7, several composite bispectrum and trispectrum parameters (amplitudes and phase) were generated. Although various literatures have provided the fundamental definition and characteristics of higher order signal processing tools, including the experimental and theoretical studies on the interpretation of bispectra of vibration signals conducted by Fackrell et al. [43-44] and Collis et al. [45]; detection of fatigue cracks in a bilinear oscillator by Rivola and White [46]; aircraft condition monitoring and faults detection using higher order spectral parameters by Howard [47]; etc. However, it is still necessary to remind readers of the current study that each of the composite higher order spectral parameters adequately provides an indication of the relationships that exist between the different frequency components that are present in the measured vibration signal in the time domain. To be more explicit, if the monitored rotating machine is operating at a speed of $1200 \mathrm{rev} / \mathrm{min}$ (i.e. $20 \mathrm{~Hz}$ in the frequency domain) a typical $\mathrm{B}_{11}$ higher order composite bispectrum parameter would provide an indication of the relationship that exist between twice $1 \mathrm{x}$ frequency component (i.e. the amplitude and phase relationship of $20 \mathrm{~Hz}$ with itself) and the their sum, $2 x$ (i.e. $40 \mathrm{~Hz}$ ). Similarly, a typical $\mathrm{B}_{12}$ composite higher order parameter would provide an indication of the relationship that exists between the $1 \mathrm{x}(20 \mathrm{~Hz})$, $2 \mathrm{x}(40 \mathrm{~Hz})$ and $3 \mathrm{x}(60 \mathrm{~Hz})$ frequency components that are present in the measured vibration signal in the time domain.

The same principle can be used to explain the $T_{111}$ and $T_{112}$ composite higher order parameters except that unlike the $\mathrm{B}_{11}$ and $\mathrm{B}_{12}$ that express the relationship that exists between two frequency components with a third (which is equal to the sum of the first), they are capable of providing the linear link between three frequency components in the measured time domain signal with a fourth (which is equivalent to the sum of the first three). This implies that typical $\mathrm{T}_{111}$ parameter for a rotating machine operating at $1200 \mathrm{rev} / \mathrm{min}(20 \mathrm{~Hz})$ shows the relationship that exists between 1x (1.e. $20 \mathrm{~Hz}), 1 \mathrm{x}(20 \mathrm{~Hz}), 1 \mathrm{x}(20 \mathrm{~Hz})$ and 3x (60 $\mathrm{Hz}$ ) while $\mathrm{T}_{112}$ parameter shows the relationship that exist between $1 \mathrm{x}(20 \mathrm{~Hz}), 1 \mathrm{x}(20 \mathrm{~Hz})$, $2 \mathrm{x}(40 \mathrm{~Hz})$ and $4 \mathrm{x}(80 \mathrm{~Hz})$. The generated parameters were individually plotted against each other (e.g. $\mathrm{B}_{11}$ amplitude vs $\mathrm{B}_{11}$ phase, $\mathrm{T}_{111}$ amplitude vs $\mathrm{T}_{111}$ phase) at the initial stage of the analysis so as to determine which combinations offer the most tangible and consistent classification results. Figure 8 shows an illustrative example of such trial combinations for all cases at $1200 \mathrm{rev} / \mathrm{min}$. It can be seen that an appreciable level of separation exists between the vibrations data collected under different machine conditions. 


\subsection{Optimisation of the eVCM faults classification parameters}

Despite the amplitude-phase retaining capabilities of composite higher order spectra that allow for the application of fewer VCM sensors during measurements (i.e. fewer data required for machine faults classification without necessarily compromising the integrity of the analysis), the eVCM process just like other machinery faults classification approaches is characterised by the generation of several parameters (e.g. $\mathrm{B}_{11}$ amplitude, $\mathrm{B}_{11}$ phase, $\mathrm{B}_{12}$ amplitude, $\mathrm{B}_{12}$ phase, etc.). Based on the premise that data reduction and simplicity are the cornerstones of the currently proposed approach, further data manipulations were explored so as to understand the parameters that best optimise the eVCM process. In Figure 8, the amplitude and phase of each composite higher order parameter is separately combined for all experimentally simulated cases at individual machine speeds (i.e. $1200 \mathrm{rev} / \mathrm{min}, 1800 \mathrm{rev} / \mathrm{min}$ and $2400 \mathrm{rev} / \mathrm{min}$ ) which was quite successful. However, the implication of the approach shown in Figure 8 is that for any number of composite higher order parameters (e.g. $\mathrm{B}_{11}, \mathrm{~B}_{12}$, $\mathrm{T}_{111}, \mathrm{~T}_{112}$, etc.) several combinations are obtainable which could further complicate the fault diagnosis process and eventually undermine the data management capability of eVCM. Therefore, a combination of just the amplitudes of only two composite higher order parameters (i.e. $\mathrm{B}_{11}$ and $\mathrm{T}_{111}$ ) was considered which provided better distinction between all cases as shown in Figure 9.

Once the features corresponding to all the experimentally simulated machine conditions of faults, speeds and foundation flexibility have been computed according to the data combination algorithm shown in Figure 7, the second and third stages of the process are based on the application of a linear classifier (based on principal component analysis) to generate a multiple speeds and multiple foundations faults classification system. At the second stage, the $p$ CCHOS features generated at individual speeds for experimental setup 1 were combined to produce the multiple speeds single machine phase of the process. In the third and final stage, the $p \mathrm{CCHOS}$ features at all speeds from both experimental rotating machines with different foundations are then combined to develop the multiple speeds and multiple foundations phase of the process.

\section{5. $\mathrm{eVCM}$ in Practice}

As briefly mentioned in the introductory section, the repair/replace times of critical and complex industrial assets such as rotating machines are often inflated by the amount of time 
spent by maintenance experts on trying to understand the root causes of failures. Hence, the development and implementation of simplified machine fault classification methods that would shorten diagnosis time is long overdue. Figure 10 shows how the eVCM algorithm effectively detected and classified all vibration data corresponding to each of the six experimentally simulated rotor-related faults into separate clusters. In addition to its ability to accurately detect and classify the machine conditions, eVCM possesses the capability to support maintenance decision-making which is very useful for the concept of eMaintenance. To further illustrate this point, C2 (misalignment) cluster is the closest to C1 (healthy) cluster due to the following reasons;

i. Since it is impracticable to achieve perfect machine alignment in real life, $\mathrm{C} 1$ machine condition was associated with some amount of misalignment.

ii. The magnitude of the experimentally simulated misalignment condition (C2) is very negligible $(0.4 \mathrm{~mm})$.

Despite the almost negligible severity of $\mathrm{C} 2$, the algorithm was still able to separate its data from those of $\mathrm{C} 1$ as well as create significant distances between their (i.e. $\mathrm{C} 1$ and $\mathrm{C} 2$ ) clusters and those containing vibration data recorded under more severe machine conditions (i.e. C3C6). The classification displayed in Figure 10 was performed using the well-known principal components analysis, where all vibration data corresponding to all experimentally simulated machine conditions at all speeds were integrated into a single algorithm. The rationale behind this approach is mainly to eliminate the need for conducting analysis on individual data sets measured at different locations of industrial machines, which implies that faults parameters already associated with a certain industrial rotating machine can be comfortably used to detect a similar fault on an identical industrial rotating machine installed at a different plant location.

With regards to enhancing automatic/remote maintenance decision-making, a better understanding of the correlation between the severities of machine conditions and the relative distances (d2-d5) between the faulty and healthy clusters can be used to determine optimum planned maintenance interventions such as the automatic injection of lubricants into a bearing operating in a very hazardous or critical environment (e.g. nuclear industry, space shuttle missions, mines, etc.) where access is very limited. 


\section{Conclusion}

The notion of regarding the maintenance function as just another cost centre under the manufacturing department has drastically changed within the past few decades. These changes can be attributed to the continuous emergence and growth of concepts such as eMaintenance that clearly depict the different ways by which maintenance can contribute towards overall business effectiveness. However, the ability of eMaintenance to attain true excellence is often impeded by the dominance of current approaches to condition monitoring of critical industrial assets such as rotating machines. In this study, effective vibration-based condition monitoring (eVCM) is proposed for simplifying machine faults detection and classification, especially identical multiple speeds rotating machines with foundation variations. eVCM also reduces condition monitoring sensor requirements as well as eliminates the complexity and data intensiveness associated with the current practice of performing separate analysis for individual machines at different speeds. Based on pilot experimental investigations, it is envisaged that $\mathrm{eVCM}$ possesses the attributes required for automatic and autonomous machine faults classification, which would be a valuable addition to the existing eMaintenance framework.

The currently proposed eVCM is solely based on the simplification of rotating machines' faults detection and classification through the optimisation of measured vibration data alone. However, it is well-known that despite the capability of VCM to offer far more reasonable lead times to rotating machine failures, other CM quantities including lube/wear debris analysis for oil lubricated systems, temperature monitoring, power measurements, sound measurements, airflow and pressure measurements, etc., can also offer valuable information about machine health. Therefore, upon further validation of the robustness of the currently defined eVCM through its application for the detection of more rotating machine faults, severities and locations, other future considerations for expanding the horizon of the concept would include the incorporation of other popular CM parameters so as to complement the current framework.

\section{Acknowledgement}

The authors would like to thank Mr Gabriel Orquera Noboa (a Reliability Engineering and Asset Management masters student at the University of Manchester, UK) for creating the three dimensional diagrams used to represent the experimental rig (Figure 4) in this study. 


\section{References}

[1] Eti, MC., Ogaji, SOT., Probert, SD. (2006). "Reducing the cost of preventive maintenance (PM) through adopting a proactive reliability-focused culture", Applied Energy, Vol. 83 No. 11, pp. 1235-1248.

[2] Mckone, K., Weiss, E. (1998). "TPM: planned and autonomous maintenance: bridging the gap between practice and research", Productions and Operations Management, Vol. 7 No 4, pp. 335-351.

[3] Al-Najjar, B. (1996). "Total quality maintenance: an approach for continuous reduction in costs of quality products", Journal of Quality in Maintenance Engineering, Vol. 2 No 3, pp. 2-20.

[4] Ljungberg, O. (1998). "Measurement of overall equipment effectiveness as a basis for TPM activities. International Journal of Operations and Production Management, Vol. 18 No 5, pp. 495-507.

[5] Coetzee, J. (1999). “A holistic approach to the maintenance problem", Journal of Quality in Maintenance Engineering, Vol. 5 No 3, pp. 276-280.

[6] Kutucuoglu, K., Hamali, J., Irani, Z., Sharp, J. (2001). "A framework for managing maintenance using performance management systems", International Journal of Operations and Production Management, Vol. 21 No 1/2, pp. 173-194.

[7] Miller, D. (2000). "Profit from preventive maintenance, bulk solids handling", Elsevier Engineering Information, Vol. 20 No 1, pp. 57-61.

[8] Al-Najjar, B., Alsyouf, I. (2004). "Enhancing a company's profitability and competitiveness using integrated vibration-based maintenance: a case study" European Journal of Operations Research, Vol. 157 No 3, pp. 643-657.

[9] Alsyouf, I. (2007). "The role of maintenance in improving companies' productivity and profitability", International Journal of Production Economics, Vol. 105 No 1, pp. 70-78.

[10] Al-Najjar, B. (2007). "The lack of maintenance and not maintenance which costs: a model to describe and quantify the impact of vibration-based maintenance on company's business", International Journal of Production Economics, Vol. 107 No 1, pp. 260-273.

[11] Arts, R.H.P.M., Knapp, G.M., and Mann, L. (1998), "Some aspects of measuring maintenance performance in the process industry", Journal of Quality in Maintenance Engineering, Vol. 4 No 1, pp. 6-11.

[12] Parida, A., Kumar, U. (2006), "Maintenance performance measurement (MPM): issues and challenges", Journal of Quality in Maintenance Engineering, Vol. 12 No 3 pp. 239251.

[13] De Groote, P. (1995), "Maintenance performance analysis: a practical approach", Journal of Quality in Maintenance Engineering, Vol. 1 No 2 pp. 4-24.

[14] Yunusa-Kaltungo, A., and Sinha, J.K. (2014). "Combined bispectrum and trispectrum for faults diagnosis in rotating machines", In Proceedings of the Institution of Mechanical Engineers, Part O: Journal of Risk and Reliability, Vol. 228 No 4, pp. 419-428.

[15] Yunusa-Kaltungo, A., Sinha, J.K., and Elbhbah, K. (2014). "An improved data fusion technique for faults diagnosis in rotating machines”, Measurement, Vol. 58, pp. 27-32.

[16] Yunusa-Kaltungo, A., Sinha, J.K., and Elbhbah, K. (2014). "HOS analysis of measured vibration data on rotating machines with different simulated faults", In Advances in 
Condition Monitoring of Machinery in Non-Stationary Operations, pp. 81-89. Springer Berlin Heidelberg.

[17] Levrat, E., and Iung, B. (2007). "TELMA: A full e-maintenance platform." In Proceedings of the Second World Congress 2007 Jun 11.

[18] Yu, R., Iung, B., and Panetto, H. (2003). "A multi-agents based E-maintenance system with case-based reasoning decision support", Engineering applications of artificial intelligence, Vol. 16 No 4, pp. 321-333.

[19] Iung, B., Levrat, E., Marquez, A.C., and Erbe, H. (2009). "Conceptual framework for eMaintenance: Illustration by e-Maintenance technologies and platforms", Annual Reviews in Control, Vol. 33 No 2, pp. 220-229.

[20] Lee, J., Ni, J., Djurdjanovic, D., Qiu, H., and Liao, H. (2006). "Intelligent prognostics tools and e-maintenance." Computers in industry, Vol. 57 No 6, pp. 476-489.

[21] Lee, J., Wu, F., Zhao, W., Ghaffari, M., Liao, L. and Siegel, D., 2014. Prognostics and health management design for rotary machinery systems-Reviews, methodology and applications. Mechanical systems and signal processing, 42(1), pp.314-334.

[22] Galar, D., Thaduri, A., Catelani, M. and Ciani, L., 2015. Context awareness for maintenance decision making: A diagnosis and prognosis approach. Measurement, 67, pp.137-150.

[23] Galar, D., Pilar, L. and Luis, B., 2010. Application of dynamic benchmarking of rotating machinery for e-maintenance. International Journal of System Assurance Engineering and Management, 1(3), pp.246-262.

[24] Emmanouilidis, C., Fumagalli, L., Jantunen, E., Pistofidis, P., Macchi, M. and Garetti, M., 2010, Condition monitoring based on incremental learning and domain ontology for condition-based maintenance. In 11th International Conference on Advances in Production Management Systems, APMS.

[25] Baglee, D., Knowles, M. and Yau, C.Y., 2012. Development of techniques to manage asset condition using new tools. In Asset Management (pp. 143-154). Springer Netherlands.

[26] Muller, A., Marquez, A.C., and Iung, B. (2008). "On the concept of e-maintenance: Review and current research", Reliability Engineering \& System Safety, Vol. 93 No 8, pp. 1165-1187.

[27] Baldwin RC. How do you spell e-maintenance? www.mt-online.com. 2004.

[28] Björling, S.E., Galar, D., Baglee, D., Singh, S. and Kumar, U., 2013, January. Maintenance knowledge management with fusion of CMMS and CM. In Proceedings of the International Conference on Data Mining (DMIN)(p. 1). The Steering Committee of The World Congress in Computer Science, Computer Engineering and Applied Computing (WorldComp).

[29] Galar, D., Wandt, K., Karim, R. and Berges, L., 2012. The evolution from e (lectronic) Maintenance to $\mathrm{i}$ (ntelligent) Maintenance. Insight-Non-Destructive Testing and Condition Monitoring, 54(8), pp.446-455.

[30] Galar, D., Palo, M., Van Horenbeek, A. and Pintelon, L., 2012. Integration of disparate data sources to perform maintenance prognosis and optimal decision making. Insightnon-destructive testing and condition monitoring, 54(8), pp.440-445. 
[31] Aboelmaged, M.G.S., 2015. E-maintenance research: a multifaceted perspective. Journal of Manufacturing Technology Management, 26(5), pp.606-631.

[32] Air Equipments Company, "Roots Blower." Available at: http://img.tradeindia.com/fp/2/001/060/119.jpg, accessed: 16 July 2015.

[33] Precision Grinding Incorporated, "Steel base plate." Available at: http://www.google.co.uk/imgres?imgurl=http://www.customsteelplate.com/Sole_Plates/G enerator_Platform.jpg\&imgrefurl, accessed: 16 July 2015

[34] Secord Construction, "Concrete foundation." Available at: http://www.secordconstruction.com/images/apollo3.jpg, accessed: 16 July 2015.

[35] Advanced Anti-vibration Components. Available at: http://www.vibrationmounts.com/RFQ/Images/Images5/V10Z32100425 iso.jpg, accessed: 16 July 2015

[36] Advanced Antivibration Components. "Spring mounts." Available at: http://www.antivibrationmethods.com/images/resize/upload/initial/mopla-5-main-pic.jpg, accessed: 16 July 2015.

[37] Niu, G., Yang, B., Pecht, M. (2010). "Development of an optimized condition-based maintenance system by data fusion and reliability-centred maintenance", Reliability Engineering and System Safety, Vol. 95, pp. 786-796.

[38] Hall, DL., Linas, J. (1997). “An introduction to multisensory data fusion", Proceedings of the IEEE, Vol. 85 No 1, pp. 6-23.

[39] Basir, O., Yuan, XH. (2007). "Engine fault diagnosis based on multi-sensor information fusion using Dempster-Shafer evidence theory", Information Fusion, Vol. 8 No 4, pp. 379-386.

[40] Yunusa-Kaltungo, A., and Sinha, J.K. (2015). "A novel fault diagnosis technique for enhancing maintenance and reliability of rotating machines", Structural Health Monitoring, Vol. 14 No 6, pp. 604-621.

[41] Yunusa-Kaltungo, A., Sinha JK., Nembhard, A. (2016). "Study on rotating machine vibration behaviour using measured vibro-acoustic signals", In Advances in Condition Monitoring of Machinery in Non-Stationary Operations, pp. 439-446, Springer International Publishing.

[42] Yunusa-Kaltungo, A. and Sinha, J.K., 2016. Sensitivity analysis of higher order coherent spectra in machine faults diagnosis. Structural Health Monitoring, 15(5), pp.555-567.

[43] Fackrell, JWA., White, PR., Hammond, JK., et al. (1995). "The interpretation of bispectra of vibration signals-1: theory", Mechanical Systems and Signals Processing, Vol. 9 No 3, pp. 257-266.

[44] Fackrell, JWA., White, PR., Hammond, JK., et al. (1995). "The interpretation of bispectra of vibration signals-1: experimental results and applications", Mechanical Systems and Signals Processing, Vol. 9 No 3, pp. 267-274.

[45] Collis, WB., White, PR., Hammond, JK. (1998). "Higher-order spectra: the bispectrum and trispectrum", Mechanical Systems and Signal Processing, Vol. 12 No 3, pp. 375-394.

[46] Rivola, A., White, PR. (1998). "Bispectral analysis of the bilinear oscillator with application to detection of fatigue cracks", Journal of Sound and Vibration, Vol. 216 No 5, pp. 889-910. 
Page 21 of 31

Journal of Quality in Maintenance Engineering

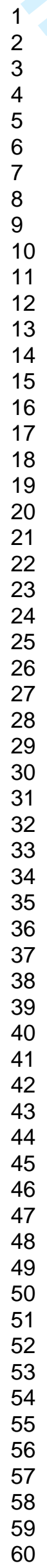

[47] Howard, IM. (1997). "Higher-order spectral techniques for machine vibration condition monitoring", Proceedings of the Institution of Mechanical Engineers, Part G: Journal of Aerospace Engineering, Vol. 211 No 4, pp. 211-219. 


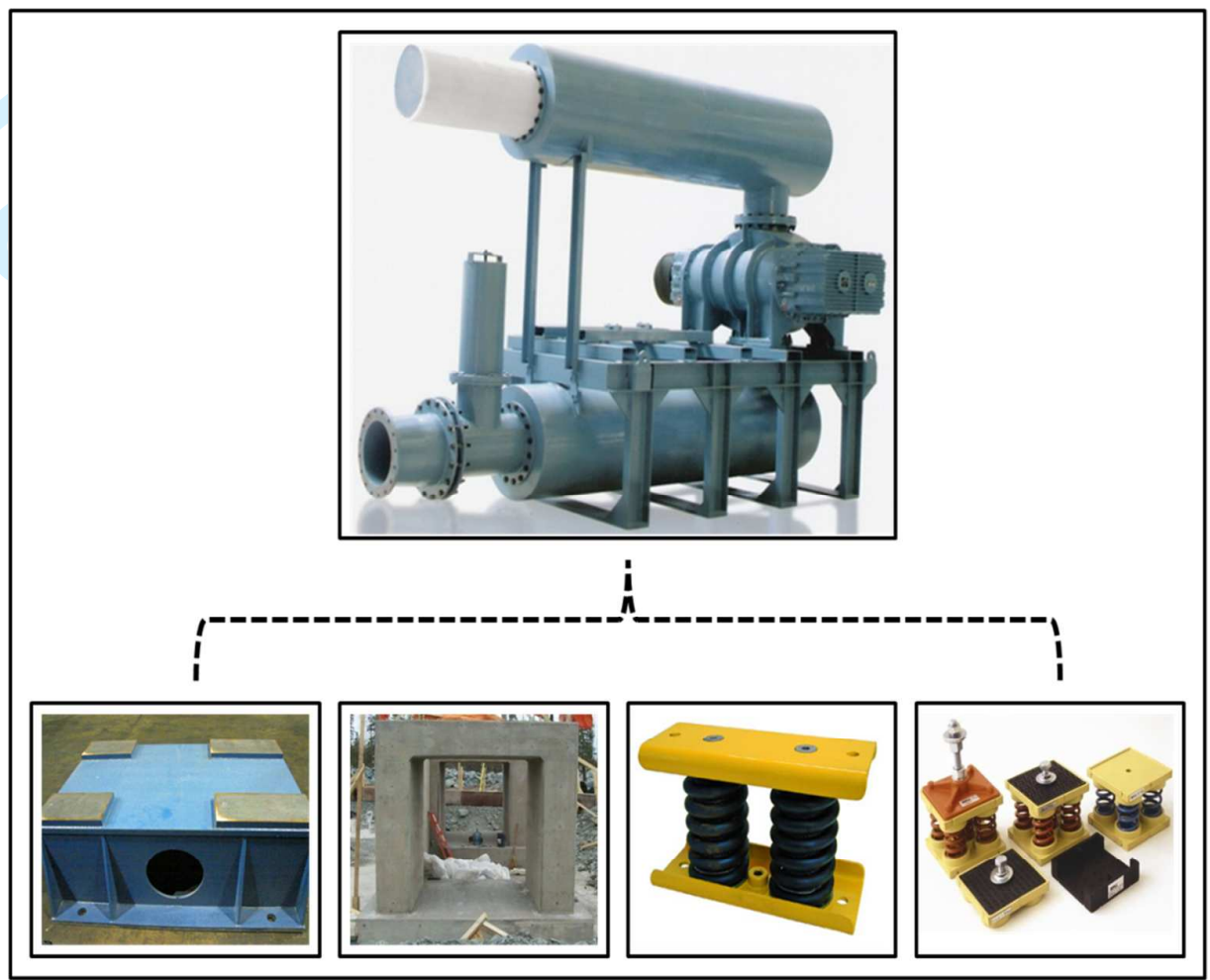

Figure 1 A typical multiple speeds cement plant roots blower with various foundation options [32-36]. 
Page 23 of 31

Journal of Quality in Maintenance Engineering

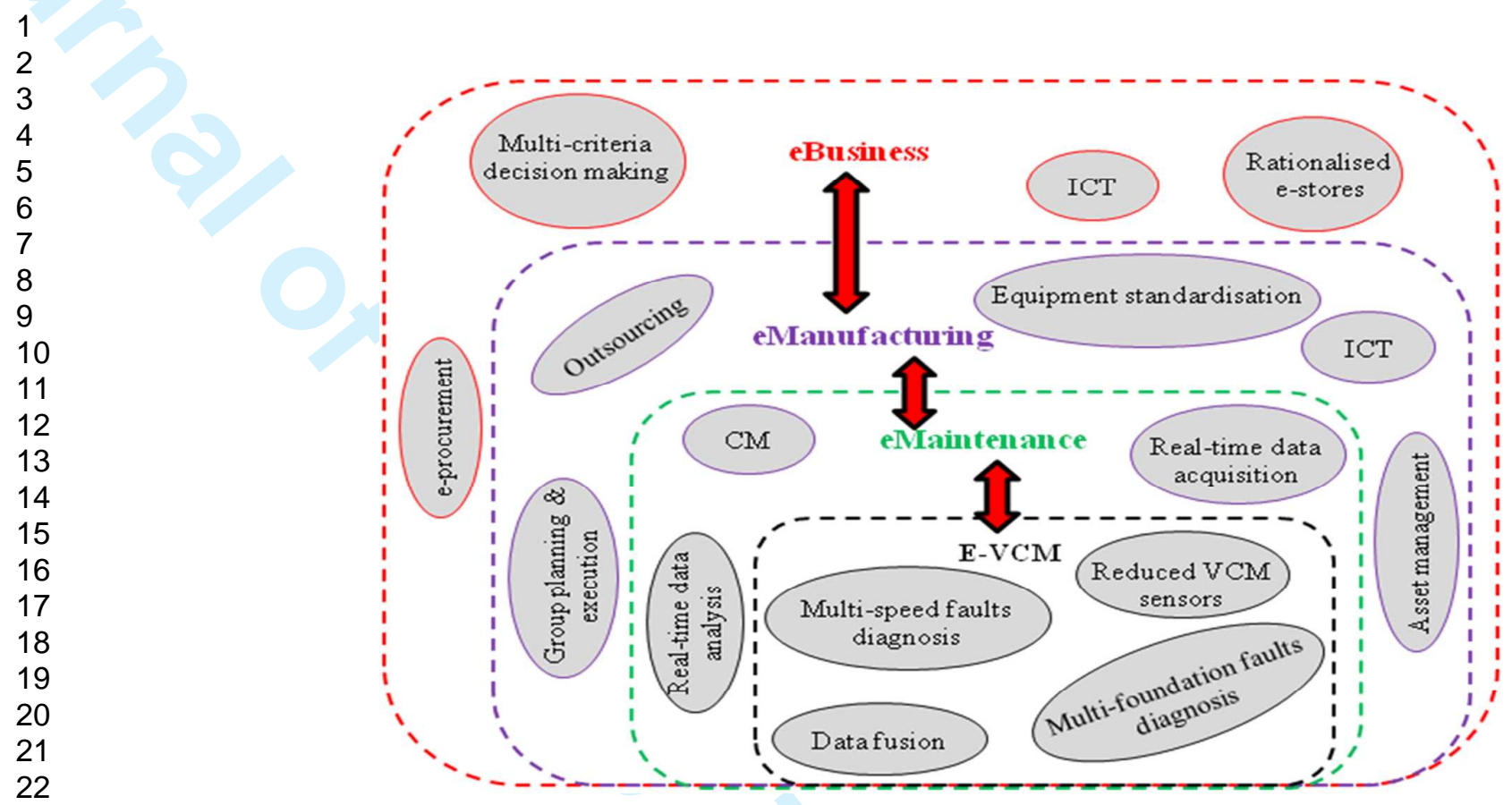

Figure 2. Integration of e- VCM, e-maintenance, e-manufacturing and e-business 

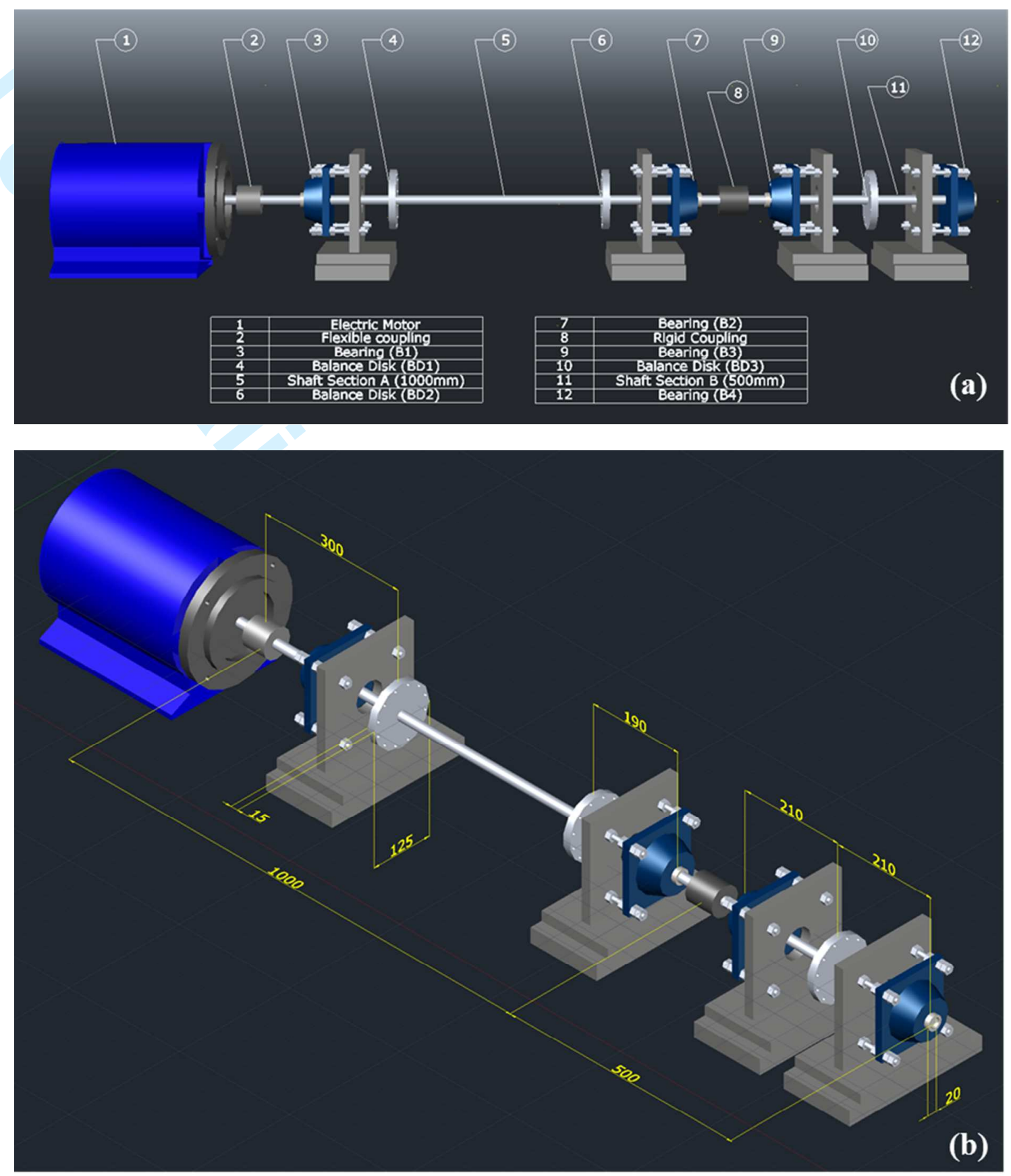

Figure 4 eVCM pilot study rig (a) rig components (b) rig dimensions 

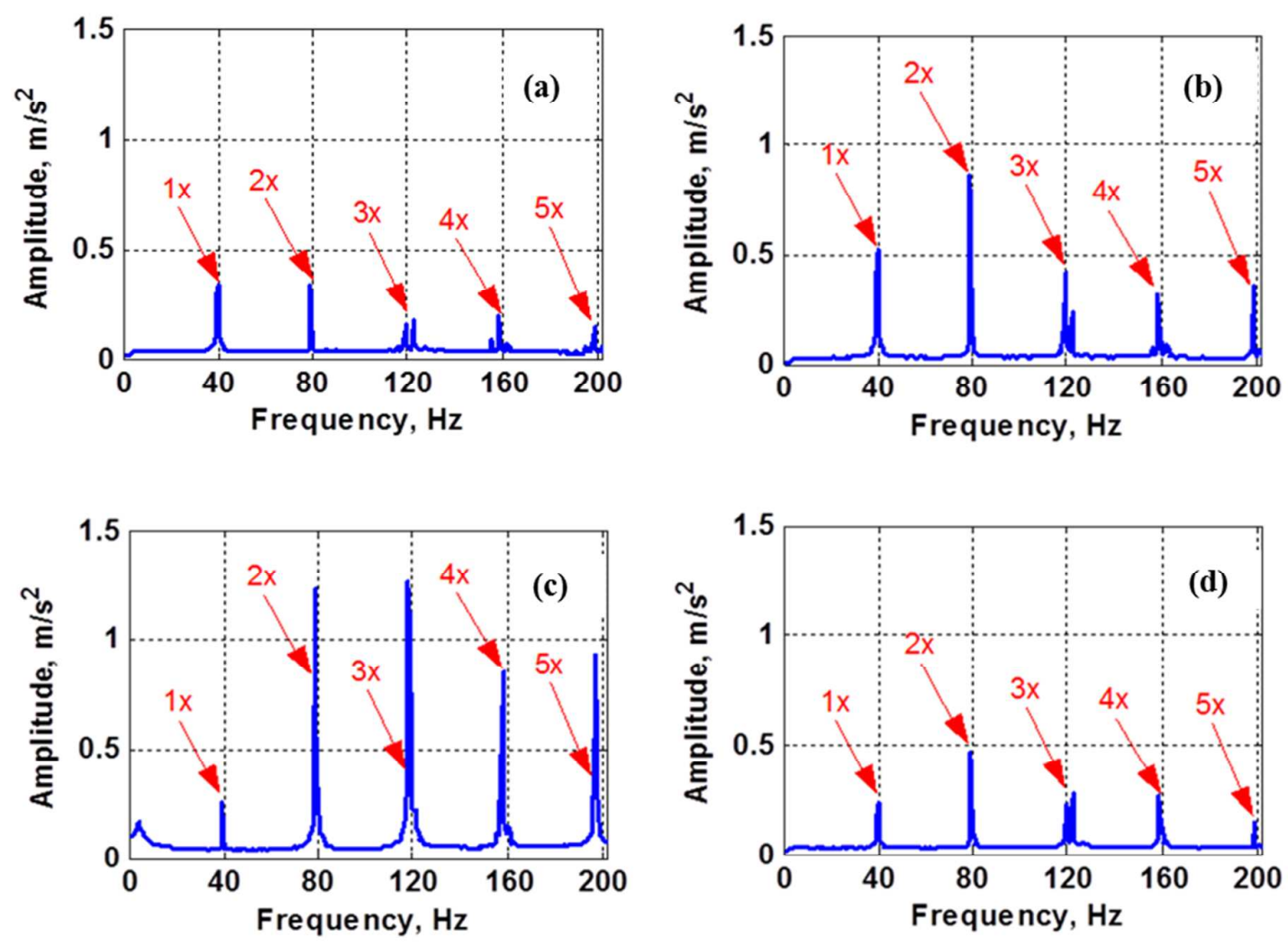

Figure 5 Typical amplitude spectra at $2400 \mathrm{rev} / \mathrm{min}$ (a) C1 (b) C2 (c) C4 (d) C6 [32] 


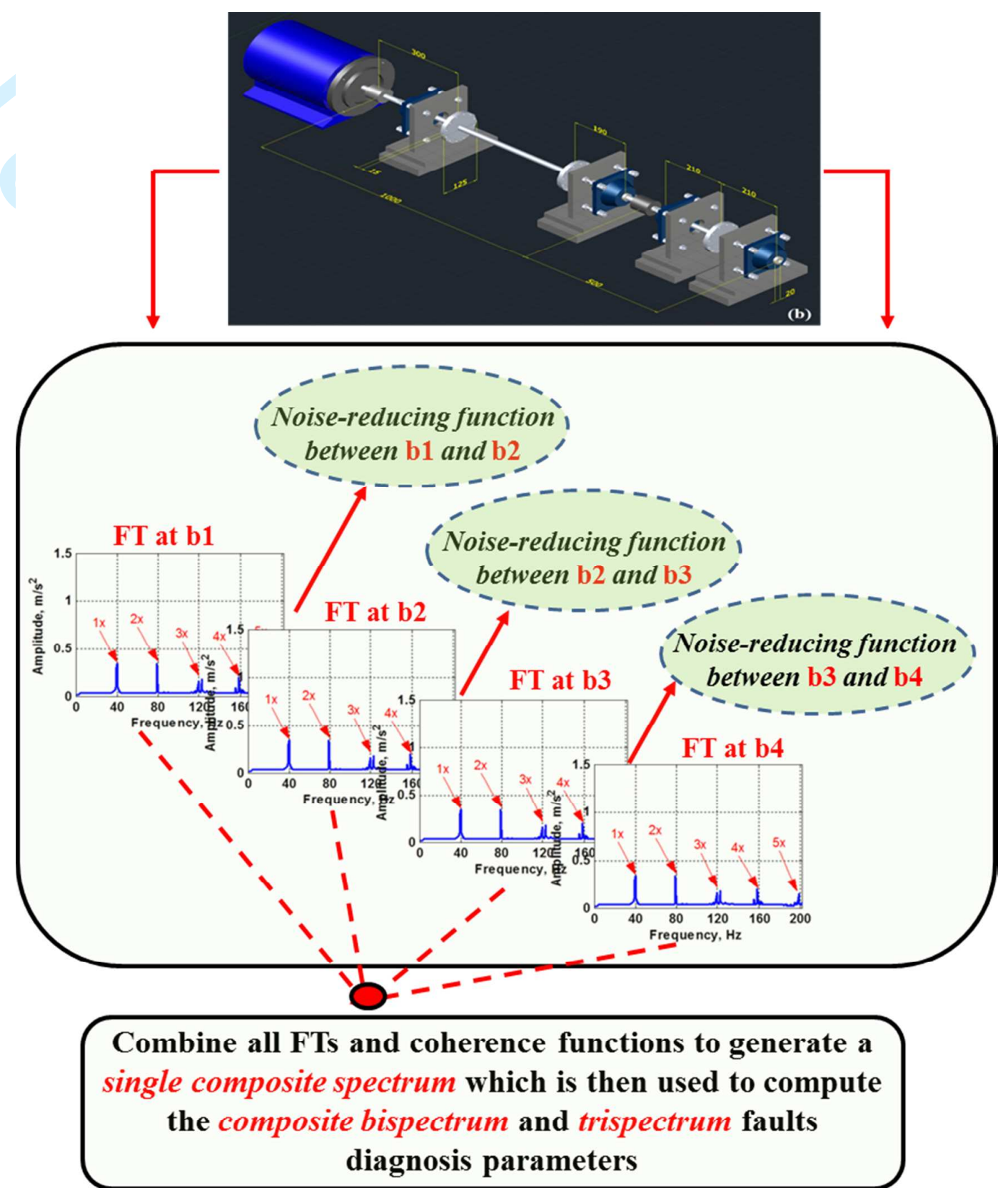

Figure 7 Diagrammatic summary of data combination process 
Page 29 of 31

Journal of Quality in Maintenance Engineering
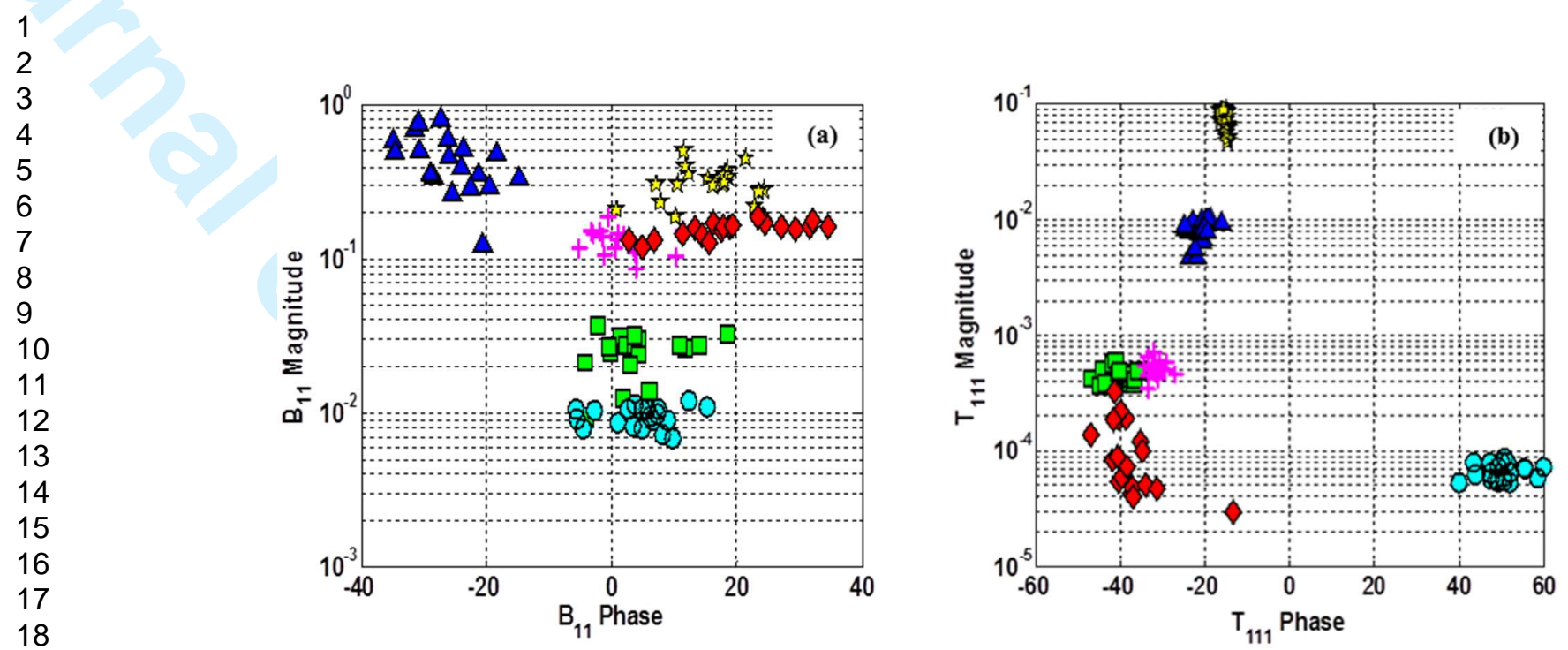

Figure 8 Separate combinations of composite bispectrum and trispectrum parameters at 1200 rev/min (a) $B_{11}$ amplitude vs $B_{11}$ phase (b) $T_{111}$ amplitude vs $T_{111}$ phase 
Journal of Quality in Maintenance Engineering

Page 30 of 31
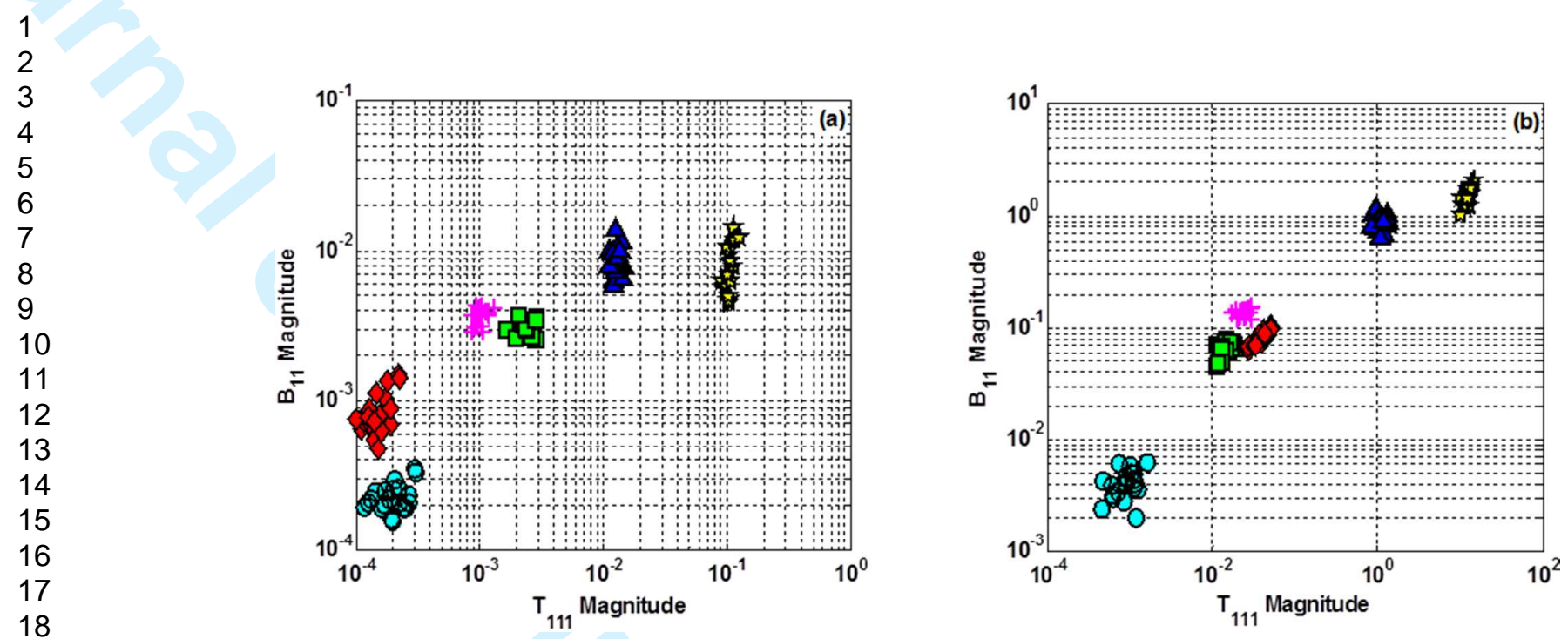

Figure 9 Combinations of the amplitudes of composite bispectrum and trispectrum parameters at $1200 \mathrm{rev} / \mathrm{min}$ (a) experimental rig 1 (b) experimental rig 2 


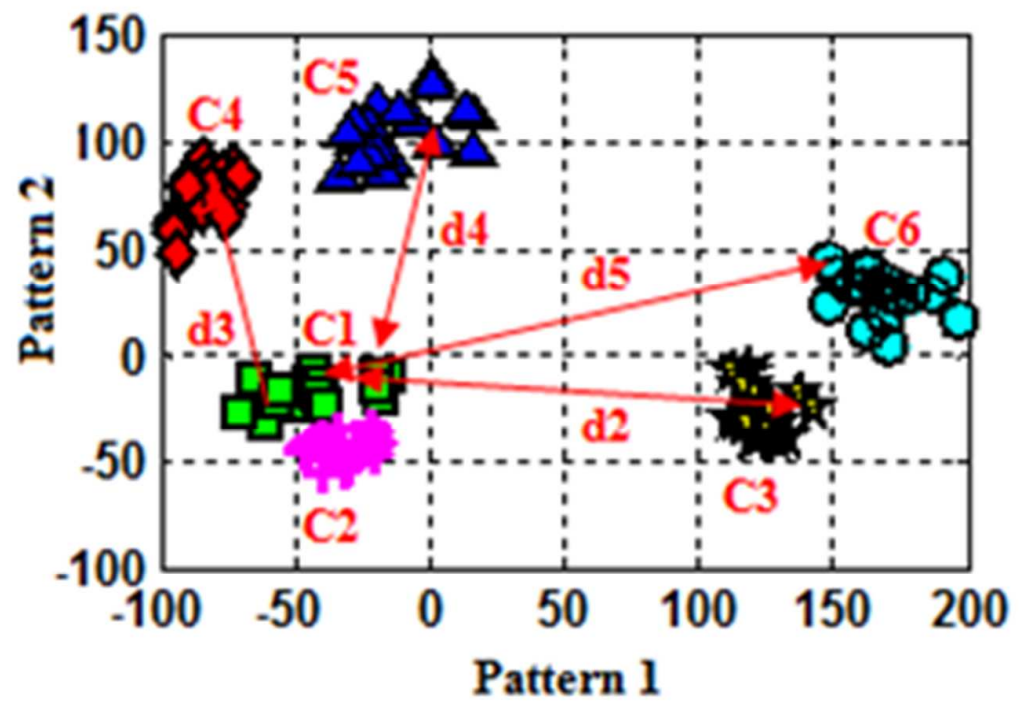

Figure 10 Classification of fused faults diagnosis parameters for rigs with different foundations. 